\title{
Alexandre Dumas, Le Spéronare
}

\section{Lise Sabourin}

\section{OpenEdition}

\section{Journals}

\section{Édition électronique}

URL : https://journals.openedition.org/studifrancesi/26552

DOI : 10.4000/studifrancesi.26552

ISSN : 2427-5856

\section{Éditeur}

Rosenberg \& Sellier

\section{Édition imprimée}

Date de publication : 1 avril 2007

Pagination : 194-195

ISSN : 0039-2944

\section{Référence électronique}

Lise Sabourin, «Alexandre Dumas, Le Spéronare », Studi Francesi [En ligne], 151 (LI | I) | 2007, mis en ligne le 30 novembre 2015, consulté le 23 novembre 2021. URL : http://journals.openedition.org/ studifrancesi/26552 ; DOI : https://doi.org/10.4000/studifrancesi.26552

\section{Ce document a été généré automatiquement le 23 novembre 2021.}

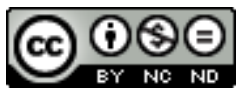

Studi Francesi è distribuita con Licenza Creative Commons Attribuzione - Non commerciale - Non opere derivate 4.0 Internazionale. 


\title{
Alexandre Dumas, Le Spéronare
}

\author{
Lise Sabourin
}

\section{RÉFÉRENCE}

ALEXANDRE DUMAS, Le Spéronare, introduction, établissement du texte et notes par JeanPierre POUGET, Paris, Champion, «Travaux de littérature moderne et contemporaine», $\mathrm{n}$. 56, 2002, pp. 693.

1 L'embarcation qui donne son nom au roman de Dumas - où sont enchâssées six nouvelles - nous invite à un voyage en Sicile, sublimation littéraire de la circumnavigation magnifiée par son aventure avec la cantatrice Caroline Ungher. Outre le texte établi sur la version publiée dans la «Revue de Paris» corrélée aux fragments du manuscrit et aux éditions ultérieures, une bibliographie et des index nominum et locorum, Jean-Pierre Pouget fournit des documents annexes (pp. 603-622) liés aux traces biographiques du périple, aux diverses étapes de composition et au lancement de ses projets sur la Méditerranée. L'introduction (pp. 7-66) relate les raisons du voyage, ses circonstances et sa datation, les sources auxquelles a eu recours Dumas, la réception critique.

2 L'intérêt porté à la Sicile dans les années 1810-30 a suscité une floraison de descriptions et de récits de voyage que les représentations des Vêpres siciliennes puis de Robert le Diable portent à leur comble pour Dumas, décidé à effectuer son périple en Méditerranée dès 1834. Le rêve médiéval associé à la présence des Normands dans l'île, amplifié par les dessinateurs, l'incite à lancer des demandes de subvention pour son voyage et des bons de souscription pour la publication prévue au retour. Si les réalités financières restreignent le déplacement de 1835 à la Sicile, l'occasion fournie par la mission ministérielle de 1846-47 en Algérie ajoutera Espagne et Afrique du Nord au programme, sans éteindre l'espérance de la complétude, encore présente dans Le Comte de Monte-Cristo en 1858.

Outre Le Spéronare, quatre autres œuvres - Le Midi de la France, Une Année à Florence, Le Capitaine Aréna et Le Corricolo - se partagent ses souvenirs du voyage italien, de Toulon 
et Florence à Rome, Arezzo, Pérouse et Naples. C'est là que Dumas rencontre la cantatrice déjà vue à Paris qui embarque sur la speronara afin de gagner Palerme en compagnie de son fiancé Henri de Ruolz-Montchal: une tempête lui fait préférer romancier! Dumas et son ami Jadin accomplissent bien le tour prévu - Taormine, Acireale, Catane et l'Etna, Syracuse et Agrigente - mais, après un détour par l'île de Pantelleria, regagnent par l'intérieur le séjour palermitain, rendu enchanteur trois semaines durant par la présence de la belle. Il faudra pourtant bien la quitter pour découvrir les îles éoliennes, retrouver Ida Ferrier à Naples, rendre visite à Grégoire XVI à Rome et regagner Paris avec quelques vicissitudes frontalières.

4 Ce matériau vécu, Dumas le complète par les souvenirs de Virgile et Diodore, des guides de l'abbé Ferrara, du poème viatique d'Ignazio Paterno Castello, pour combler ses lacunes concernant par exemple les festivités de la sainte Rosalie à Palerme, le tremblement de terre de Messine ou le surgissement de l'île volcalnique Julia. Il se fonde en outre particulièrement sur les Pensées et souvenirs historiques et contemporains de Michele Palmieri di Miccichè pour la trame des nouvelles insérées, largement étoffées personnellement ainsi que par d'autres sources.

5 Même si Le Spéronare ne cherche pas à constituer un véritable récit de voyage en Sicile, Dumas a su lui donner une tonalité d'impressions subjectives où brille son art de conteur: dialogues vifs, détails amusants, anecdotes piquantes constituent un «laboratoire de l'œuvre romanesque à venir» (p. 51). L'accueil critique immédiat a été quasi inexistant, mais, outre Dumas fils, Maupassant sait apprécier ce roman que Ramon Fernandez et André Bellessort louent ensuite loué. Il est donc heureux que JeanPierre Pouget, en notre époque attentive à la relation viatique, nous permette de le relire, ne serait-ce que pour mieux en cerner les différences génériques. 